\section{IMAGE UNAVAILABLE FOR COPYRIGHT REASONS}

Twins, from Dale et $a l^{3}$

are in the etiology of developmental delays. This has ramifications for the role of the early family environment (prenatal and postnatal) in the development of vocabulary skills. One suggestion in these data is that the family (through prenatal care, postnatal stimulation and education) plays a powerful role in the vocabulary skills of children in the normal range. However, faced with a child with seriously delayed growth, parents and professionals need to look for biological causes rather than pre- or postnatal environmental factors (such as poor nutrition) that are commonly invoked as causative ${ }^{3}$.

Although the results of this study are a beginning, it is worth bearing in mind that they are based on a select sample of twins and pertain to parental reports of expressive vocabulary with no intention or means to assess receptive skills or vocabulary comprehension. Moreover, the authors, with good reason, excluded a large number of twins based on criteria that may have artificially reduced the proportion of environmental variance in the delayed sample. Consequently, the everyday delayed child seen by parents and professionals probably includes a more heterogenous collection of etiologies than is represented in the Dale study. This aside, we should look forward to future reports on this impressive sample of twin pairs. In particular it will be interesting to see how the sample changes with age and how the delayed and typicallydeveloping children select or modify their environment based on their genetic predispositions ${ }^{1}$.

1. Gilger, J.W. Behavioral genetics: Concepts for research in language and language disabilities. Journal of Speech and Hearing Research 38, 1126-1142

\title{
The unwinding road to cancer
}

What causes a cell to switch up a gear from normal to cancerous growth? Known culprits include mutated tumor suppressor genes, cell cycle regulators and DNA repair proteins. Now, according to a report by Oliver Delattre and co-workers in Nature (394, 203-206, 1998), we can add chromatin-remodeling proteins to this list. Not only that, but recent studies from the Kingston and Kornberg groups (Cell 94, $17-27,29-34,1998)$ give us some clues as to how these proteins work.

In chromatin, the tightly wound DNA cannot be accessed by the transcriptional machinery unless the structure of the chromatin is somehow disrupted. Based on studies in yeast, the human (h)SWI/SNF multiprotein complex has been one of the main contenders for this function, and Delattre and colleagues now implicate its smallest subunit, hSNF5/INI1, in tumorigenesis.

The authors homed in on the hSNF5/INII gene while searching for mutations that cause malignant rhabdoid tumorsextremely aggressive cancers found mainly in the brain, kidney and soft tissues of young children. A genetic characteristic of the condition is deletion of region 11.2 on the long arm of chromosome 22, so the authors mapped this stretch of DNA from 13 cell lines. They narrowed down the deleted area to the smallest region of overlap between the cell lines and found that this region was present in hSNF5/INII.

\section{IMAGE UNAVAILABLE FOR COPYRIGHT REASONS}

The investigators next looked at an additional seven cell lines and found frameshift or nonsense mutations of hSNF5/INI 1 in six of them. Most of these mutations led to truncation of a conserved 200-amino-acid domain, and mutation of one allele was associated with loss of the other allele. This led the authors to propose that mutations in hSNF5/INI1 contribute to oncogenesis.

But how might hSWI/SNF do this? Cue Kingston and colleagues, who did some neat biochemistry to show that the normal function of hSWI/SNF is to facilitate an exchange between normal chromatin and an altered, more accessible structure. Kornberg and collaborators came to essentially the same con-
(1995).

2. Pinker, S. \& Bloom, P. Natural language and natural selection (and commentaries). Brain Behav. Sciences 13, 707-784 (1990).

3. Smith, S.D., Gilger, J.W. \& Pennington, B.F. Dyslexia and other language/learning disorders. In Emory and Rimoin's Principles and Practices in Medical Genetics (eds. D. Rimoin, J.Connor \& R. Pyeritz), pages 1767-1789 (Churchill Livingstone, New York, 1996).

4. Bates, E., Bretherton, I., Beeghly-Smith, M. \& McNew, S. Social bases of language development: A reassessment. In Advances in child development and behavior (eds. H. W. Reese \& L.P. Lipsitt), pages 8-68 (Academic Press, New York, 1982).

5. Dale, P.S. et al. Genetic influence on language delay in two year-old children. Nature Neurosci. 1, 324-328 (1998).

6. Gilger, J.W., Borecki, I., Smith, S.D., DeFries, J.C., \& Pennington, B.F. The etiology of extreme scores for complex phenotypes: An illustration using reading performance. In Developmental dyslexia: Neural, cog. nitive and genetic mechanisms (eds. C. Chase, $\mathrm{G}$. Rosen, \& G. Sherman) pages 63-85 (York Press, Baltimore, Maryland, 1996).

7. Shaywitz, S.E., Escobar, M.D., Shaywitz, B.A., Fletcher, J.M, \& Makuch, R. Evidence that dyslexia may represent the lower tail of a normal distribution of reading ability. New Engl. I. Med. 326, 145-150 (1992).

8. Achenbach, T.M. Developmental psychopathology. (John Wiley \& Sons Inc., New York, 1982).

Department of Speech-Language-Hearing Sciences and Disorders, and the Human Biology Program, University of Kansas

Lawrence, Kansas 66045, USA

email:gilger@falcon.cc.ukans.edu

clusions by studying RSC, a yeast chromatinremodeling complex that is related to SWI/SNF.

The idea is that hSWI/SNF binds two nucleosome cores and, powered by ATP hydrolysis, converts them to an alternative, stable conformation - so stable, in fact, that it can exist in the absence of hSWI/SNF (pictured). Both groups used DNA-digestion assays to show that the new species has altered contacts between the histones and DNA, although it contains the same overall ratio of DNA to histones. They also found that the reactions were reversible, so the altered chromatin could be converted back to the original structure in the presence of hSWI/SNF.

The task now is to relate these findings to cell proliferation and tumorigenesis. Presumably, mutated hSWI/SNF cannot convert chromatin to the more accessible structure, effectively switching off gene expression. There is already a precedent for this: the retinoblastoma tumor suppressor protein represses gene expression by modulating the architecture of chromatin, albeit in a completely different way. And the emerging picture is that the proteins involved in governing the structure of chromatin are, at least in some cases, responsible for sending cells down the road to cancer. Alison Mitchell, Nature 